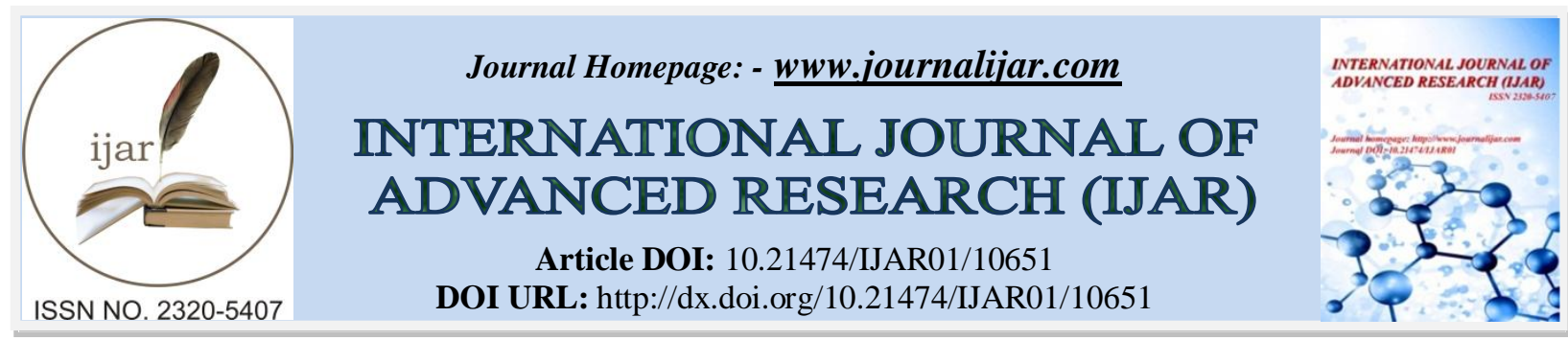

RESEARCH ARTICLE

\title{
PULMONARY MANIFESTATIONS DURING SPONDYLARTHRITIS
}

\author{
Tarik Youssoufi, Mehdi Boudhar, Fatima Zahra Haddani, Oulahri Soumia, Youssef El. Jebbouri, Abdelhafid \\ Guich and Hasna Hassikou \\ Rheumatologic Department, Military Hospital of Moulay Ismail, Meknes - Morocco.
}

\section{Manuscript Info}

Manuscript History

Received: 10 January 2020

Final Accepted: 12 February 2020

Published: March 2020

Key words:-

Spondylarthritis, Lung, Standard Radiography, Respiratory Functional Exploration, Thoracic CT Scan

\section{Abstract}

Introduction: Pleuropulmonary involvement in spondylarthritis has long been considered a rare and late manifestation of this group of diseases because of its asymptomatic nature and the failure of chest $\mathrm{X}$ ray to detect early lung injury. However, with the advent of CT scanning, a wide variety of sub-clinical lung lesions that were not detectable on standard radiography have been objectified.

Objectives: Research the correlations between lung involvement and the different characteristics and types of spondylarthritis.

Materials and Methods: This is a retrospective cohort-type observational epidemiological study, conducted over a 3-year period. 133 patients with spondylarthritiswere included. All had a detailed clinical examination, chest X-ray, respiratory function tests and chest CT scan.

Results: 133 patients with spondyloarthropathies; 57 spondyloarthritis, 54 psoriatic arthritis and $22 \mathrm{IBD}$-associated spondyloarthritis. M/F sex ratio of 1.14. Chest CT scan revealed abnormalities in 58 patients (43.6\%) with 13 symptomatic respiratory patients, whereas the standard chest X-ray was abnormal in only 19 cases. Multivariate analysis showed factors associated with CT abnormalities in patients over 60 years of age, with dactylitis, and cervical stiffness. Factors associated with ventilatory abnormalities have also been found in patients over 60 years of age, cervical stiffness, coxitis, inflammatory syndrome, and osteoporosis. No influence of the type of spondylitis was found on the presence or type of lung involvement $(\mathrm{p}=0.230)$.

Conclusion: This study allowed us to detect certain factors associated with lung damage, revealed early on thoracic CT and EFR, in patients with SpA. It would be judicious to propose this examination in patients with functional respiratory signs even if the standard radiography is normal, even for a wider screening in any SpA patient even asymptomatic.

Copy Right, IJAR, 2020,. All rights reserved.

\section{Introduction:-}

Certain clinical and radiological evidence, later associated with genetic arguments, has led to the grouping together within the same diagnostic entity of a certain number of rheumatological diseases, which seem to come from very different horizons. This entity corresponds to the spondylarthritis. 
From a clinical and radiological point of view, these diseases all associate, although to varying degrees, an axial, spinal and sacroiliac syndrome, a peripheral articular and/or enthesitic syndrome, and an extra rheumatological syndrome.

The lung is a classic site of extra-articular involvement in spondylarthritis (SpA). Pulmonary manifestations have been described mainly in the axial forms and in particular in ankylosing spondylarthritis (AS). Their incidence ranges from 0 to $45 \%$ [1]. They are partly related to thoracic rigidity secondary to costo-vertebral joint involvement, but also to pleuropulmonary lesions, the most frequent of which are classic apical fibrosis, interstitial infiltrations and pleural thickening. However, as it is often asymptomatic and chest X-ray cannot detect early lung lesions, it was long considered a rare and late manifestation.

We propose in this work, through a prospective study including 133 cases of spondylitis collected at the rheumatology department of the Moulay Ismail Meknes military hospital:

1. To describe the different stages that contributed to the recognition of pleuropulmonary involvement (clinical, imaging, functional respiratory exploration, broncho-alveolar lavage and possible biopsy).

2. Specify the type, topography and frequency of lesions according to the technique used.

3. To look for the following correlations between the results of standard X-rays, CT scans, and data from functional respiratory exploration; with the distribution of enthesic, axial and peripheral rheumatic damage; the duration of evolution; the severity of the spondyloarthritis, and finally, with the quality of management.

\section{Materials And Methods:-}

This is a prospective study, carried out over a period of 3 years (from January 2017 to December 2019), conducted at the Rheumatology Department at the Moulay Ismail Military Hospital in Meknes.

Inclusion Criteria :The study population consisted of 133 patients with Spondylitis as defined by ASAS 2009 criteria, CASPAR criteria or Chronic Inflammatory Bowel Disease (IBD) diagnosed by a gastrologist associated with Spondylitis.

Exclusion Criteria :Patients who did not have a complete record or were lost to follow-up were excluded.

After patient consent and information, a number of data were collected and patients were given a rheumatologic evaluation and routine pulmonary exploration.

All the data collected at inclusion were reported on an exploitation sheet which specified the sociodemographic aspects of the study population; the clinical, paraclinical and therapeutic characteristics of spondylitis.

Data were entered and coded on a Microsoft Excel file and analyzed using SPSS v20 software.

The results were reported in graphs and commented tables.

Descriptive data are presented as mean $+/$ - standard deviation for quantitative variables and as frequency and percentage for qualitative variables.

A $\mathrm{p}<0.05$ was considered significant.

\section{Results:-}

Our study included 133 patients with spondylitis. - 43\% had ankylosing spondylitis $(\mathrm{n}=57)$, 41\% had psoriatic arthritis $(n=54)$, and $16 \%$ had IBD-associated spondylitis $(n=22)$. The average age of our patients is $47 \pm 12$ years with extremes ranging from 18 to 72 years. The sex ratio is $\approx 1.13$ male/female ( 71 males to 62 females).

The mean age of onset of spondyloarthritis is 38.31 years with a standard deviation of 12.19 years and a range of [14 - 69 years]. And the average duration of progression of spondylitis in our patients is $8.74 \pm 7.53$ years with a range of [1 - 32 years].

The frontal chest X-ray was abnormal in 19 of our patients, i.e. $14.3 \%$. It showed an interstitial syndrome in 12 cases, mediastinal enlargement in 5 cases and 2 cases of intra-parenchymal opacities. 
The CT scan revealed abnormalities in 58 patients or $43.6 \%$ of the cases studied (13 of which were symptomatic in respiratory terms), whereas the standard chest X-ray detected abnormalities in only 19 patients.

These abnormalities included: interstitial syndrome $(n=25)$, emphysema $(n=9)$, micronodules $(n=8)$, mediastinal adenopathies $(n=7)$, bronchiectasis $(n=4)$, apical fibrosis $(n=3)$, pleural thickening $(n=2)$.

Among the 58 patients with lung disease objectively identified on CT scan: 26 have spondylitis, 21 have psoriatic arthritis, and 11 have spondylitis associated with IBD (figure 1).

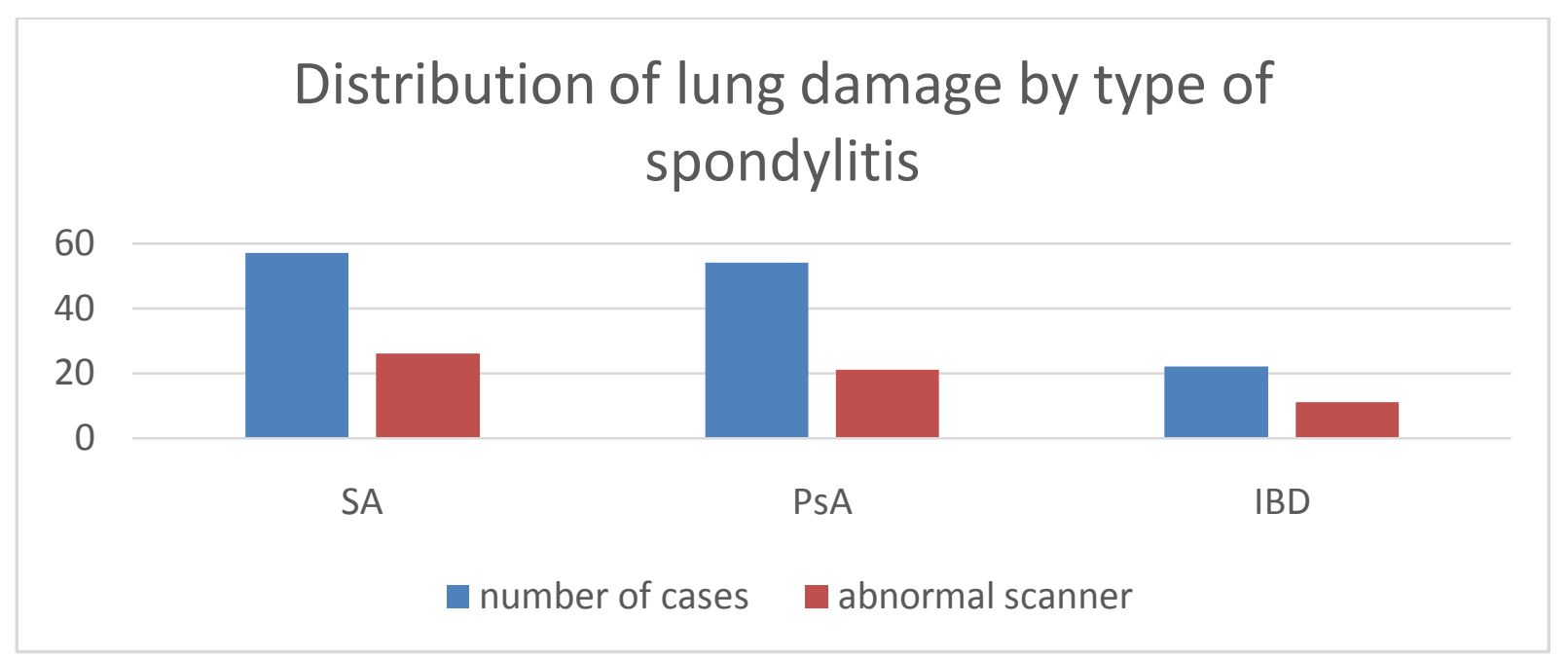

Figure 1:- Distribution of CT lung disease by type of spondyloarthritis.

Comparison results between patients with and without lung CT scans are summarized in Table 1;

Table 1:- Comparison of results in patients with and without lung CT lesions.

\begin{tabular}{|c|c|c|c|c|}
\hline & & SpA with scannographic damage & SpA without scan damage & \multirow[t]{2}{*}{$\mathrm{P}$} \\
\hline & & $(n=58)$ & $(n=75)$ & \\
\hline \multicolumn{2}{|l|}{ SpA type: } & $26(44,8 \%)$ & $31(41,3 \%)$ & 0,623 \\
\hline \multirow{3}{*}{\multicolumn{2}{|c|}{$\begin{array}{ll}- & \text { SA } \\
- & \text { PsA } \\
- & \text { IBD }\end{array}$}} & $21(36,2 \%)$ & $33(44 \%)$ & \\
\hline & & $11(18,9 \%)$ & $11(14,6 \%)$ & \\
\hline & & & & \\
\hline \multicolumn{2}{|l|}{ Age (years), m+/- SD } & $52,43 \pm 11,75$ & $42,98 \pm 11,54$ & 0,049 \\
\hline \multicolumn{2}{|l|}{ Sex M/F, n (\%) } & $33(56,8 \%) / 25(43,1 \%)$ & $38(50,6 \%) / 37(49,3 \%)$ & 0,475 \\
\hline \multicolumn{2}{|l|}{ Smoking, n (\%) } & $29(50 \%)$ & $27(36 \%)$ & 0,105 \\
\hline \multicolumn{2}{|c|}{ Starting age (years), $\mathrm{m}+/-\mathrm{SD}$} & $42,46 \pm 11,87$ & $35,1 \pm 11,52$ & 0,053 \\
\hline \multicolumn{2}{|c|}{ Development period (years), $\mathrm{m}+/-\mathrm{SD}$} & $9,84 \pm 7,92$ & $7,89 \pm 7,15$ & 0,201 \\
\hline \multicolumn{2}{|l|}{ Obesity } & $18(31 \%)$ & $31(41,3 \%)$ & 0,22 \\
\hline \multirow[t]{3}{*}{ Axial damage (\%) } & Low back pain & $35(93,75 \%)$ & $32(94,11 \%)$ & 0,043 \\
\hline & dorsalgia & $29(81,25 \%)$ & $24(67,64 \%)$ & 0,035 \\
\hline & Cervicalgia & $15(43,75 \%)$ & $11(29,41 \%)$ & 0,106 \\
\hline \multirow[t]{2}{*}{ Peripheral damage $(\%)$} & Arthralgia & $52(89,6 \%)$ & $67(89,3 \%)$ & 0,942 \\
\hline & Arthritis & $37(63,8 \%)$ & $42(56 \%)$ & 0,364 \\
\hline \multirow[t]{2}{*}{ Enthesis damage, $(\%)$} & dactylitis & $43(74,1 \%)$ & $43(57,3 \%)$ & 0,044 \\
\hline & fessalgia & $45(77,5 \%)$ & $51(68 \%)$ & 0.221 \\
\hline \multicolumn{2}{|l|}{ DAS 28 CRPI, m+/-DS } & $4,23 \pm 1,46$ & $3,93 \pm 1,49$ & 0,12 \\
\hline \multicolumn{2}{|l|}{ ASDAS CRP, m+/-DS } & $3,31 \pm 1,49$ & $3,53 \pm 1,37$ & 0,14 \\
\hline \multicolumn{2}{|c|}{ SR (1 ère heure) $(\mathrm{mm}), \mathrm{m}+/-\mathrm{DS}$} & $43,43 \pm 31,86$ & $20,78 \pm 18,92$ & 0,13 \\
\hline \multicolumn{2}{|l|}{ CRP,$m+/-D S$} & $11,03 \pm 10,45$ & $14,32 \pm 16,34$ & 0,19 \\
\hline \multicolumn{2}{|l|}{ osteoporosis } & $27(46,5 \%)$ & $15(20 \%)$ & 0,01 \\
\hline \multicolumn{2}{|l|}{ Coxite, n (\%) } & $14(24,1 \%)$ & $17(22,6 \%)$ & 0,842 \\
\hline
\end{tabular}




\begin{tabular}{|l|l|l|l|}
\hline Anti TNF treatment, $\mathrm{n}(\%)$ & $20(34,5 \%)$ & $17(22,6 \%)$ & 0,132 \\
\hline
\end{tabular}

Univariate analysis showed statistically significant correlations with :

1. Advanced patient age $(\mathrm{p}=0.049): 77.3 \%$ of patients over 60 years of age (17 of 22 patients) had chest CT abnormalities compared to $36.9 \%$ of subjects under 60 years of age,

2. The presence of dactylitis $(\mathrm{p}=0.044)$

3. Lumbar stiffness $(\mathrm{p}=0.043)$ and back stiffness $(\mathrm{p}=0.035)$

4. Osteoporosis $(\mathrm{p}=0.01)$

Multivariate analysis showed factors associated with scan abnormalities in :

1. Patients over 60 years of age $(\mathrm{ORa}=8.53,95 \% \mathrm{CI}[2.29-31.70])$,

2. Patients with dactylitis (ORa=2.43, IC95\% [1.05-5.64]),

3. Patients with cervical stiffness $(\mathrm{ORa}=2.83,95 \% \mathrm{CI}[1.08-7.40])$.

On the other hand, there was no statistically significant difference between patients with and without pulmonary CT scan involvement with respect to sex, age of onset of disease, smoking, the different associated defects, peripheral distribution of rheumatic involvement, inflammatory syndrome, activity of the peripheral form (DAS 28 CRP and DAS 28 VS), activity of the axial form (ASDAS CRP and ASDAS VS) and the different therapies taken by the patient.

Comparison results between patients with and without pulmonary ventilatory disorders are summarized in Table 2;

\begin{tabular}{|c|c|c|c|c|}
\hline & & SpA avec Troubles EFR & SpA sans Troubles EFR & $\mathrm{P}$ \\
\hline & & $(\mathrm{n}=49)$ & $(\mathrm{n}=84)$ & \\
\hline Type SpA & & $25(51 \%)$ & $32(38,1 \%)$ & 0,097 \\
\hline SA & & $14(28,5 \%)$ & $40(47,6 \%)$ & \\
\hline RPso & & $10(20,4 \%)$ & $12(14,2 \%)$ & \\
\hline MICI & & & & \\
\hline Age (ans), $m+/-$ DS & & $52,04 \pm 13,10$ & $44,22 \pm 11,25$ & 0,01 \\
\hline Sexe H/F, n (\%) & & $29(59,1 \%) / 20(40,8 \%)$ & $42(50 \%) / 42(50 \%)$ & 0,306 \\
\hline Tabagisme, $\mathrm{n}(\%)$ & & $24(48,9 \%)$ & $32(38 \%)$ & 0,220 \\
\hline Age de début (ans), $m+/-\mathrm{D}$ & & $41,65 \pm 13,82$ & $36,3 \pm 10,75$ & 0,022 \\
\hline Durée d'évolution (ans), $\mathrm{m}$ & & $10,22 \pm 7,82$ & $7,88 \pm 7,26$ & 0,201 \\
\hline Obésité & & $18(36,7 \%)$ & $31(36,9 \%)$ & 0,444 \\
\hline Atteinte axiale (\%) & Lombalgie & $35(71,4 \%)$ & $33(39,2 \%)$ & 0,01 \\
\hline & dorsalgie & $30(61,2 \%)$ & $23(27,4 \%)$ & 0,000 \\
\hline & Cervicalgie & $15(30,6 \%)$ & $11(13 \%)$ & 0,014 \\
\hline Atteinte periphérique (\%) & Arthralgies & $41(83 \%)$ & $78(92,8 \%)$ & 0,096 \\
\hline & Arthrites & $27(55,1 \%)$ & $52(62 \%)$ & 0,441 \\
\hline dactylite & & $31(63,2 \%)$ & $55(65,4 \%)$ & 0,797 \\
\hline DAS 28 CRPI, m+/-DS & & $3,43 \pm 1,78$ & $3,62 \pm 1,78$ & 0,12 \\
\hline ASDAS CRP, $m+/$-DS & & $3,25 \pm 1,98$ & $3,28 \pm 1,67$ & 0,14 \\
\hline VS (1 ère heure) $(\mathrm{mm}), \mathrm{m+}$ & & $39,5 \pm 34,32$ & $25,2 \pm 21,6$ & 0,13 \\
\hline $\mathrm{CRP}, \mathrm{m}+/-\mathrm{DS}$ & & $12,53 \pm 11,5$ & $15,02 \pm 15,90$ & 0,19 \\
\hline ostéoporose & & $25(51 \%)$ & $17(20,2 \%)$ & 0,01 \\
\hline Coxite, n (\%) & & $17(34,6 \%)$ & $14(16,6 \%)$ & 0,018 \\
\hline Traitement par des Anti TI & n (\%) & $17(34,7 \%)$ & $20(23,8 \%)$ & 0,132 \\
\hline
\end{tabular}

Table 2:- Comparison of results in patients with and without ventilatory disorders.

Univariate analysis showed statistically significant correlations with :

1. The advanced age of the patients $(\mathrm{p}=0.01)$ over 60 years of age,

2. Age of onset of disease $(\mathrm{p}=0.022)$

3. Axial injury: lumbar stiffness $(p=0.01)$, dorsal stiffness $(p=0.000)$ and cervical stiffness $(p=0.014)$.

4. The presence of Coxite $(\mathrm{p}=0.018)$

5. Osteoporosis $(\mathrm{p}=0.01)$ 


\section{Multivariate analysis showed factors associated with ventilatory abnormalities in :}

1. Patients over 60 years of age $(\mathrm{ORa}=8.34,95 \% \mathrm{CI}[1.78-38.75])$,

2. Cervical stiffness $(\mathrm{ORa}=3.56,95 \%$ CI $[1.18-10.74])$,

3. Coxite (ORa $=3.66,95 \%$ CI $[1.23-10.89])$,

4. Inflammatory syndrome $(\mathrm{ORa}=2.73,95 \% \mathrm{CI}[1.04-7.19]$,

5. Osteoporosis $(\mathrm{ORa}=7.06,95 \% \mathrm{CI}[2.66-18.69]$.

On the other hand, there was no statistically significant difference between patients with and without ventilatory disorders with regard to sex, smoking consumption, the different associated defects, the peripheral distribution of the rheumatic disorder outside the severe location (coxitis), the activity of the peripheral form (DAS 28 CRP and DAS 28 VS), the activity of the axial form (ASDAS CRP and ASDAS VS) and the different therapies taken by the patients.

\section{Discussion:-}

Lung involvement is one of the extra-articular conditions described in spondylitis. It is usually asymptomatic and occurs in later stages of the disease [2,3]. 2,3] It is dominated by restrictive disorders. Pleural lesions and those of the pulmonary parenchyma are more rarely sought because they are often asymptomatic. Among these, apical fibrosis, bronchiectasis, emphysema, frosted glass images, micronodules, pleural thickening and thickening of the bronchial wall are the most commonly described. A lower incidence of empyema, cor pulmonale [4] and pneumothorax [5] has been reported.

The majority of studies concerning lung disease focus on spondylarthritis (AS), very few on psoriatic arthritis (PsA) and other forms of spondyloarthritis (SpA). Therefore, we will compare our results with the various studies on lung involvement in Ankylosing Spondylitis, as well as some work discussing this complication in skin psoriasis or chronic inflammatory bowel disease.

The frequency of lung involvement varies between series but can be as high as $70 \%$ in series using CT scans for screening.

Prior to the introduction of CT, previous studies of the association between spondylitis and abnormalities of the lung parenchyma were largely based on standard radiography and respiratory functional investigations. This explains the low frequency of this condition in the early literature. Rosenow et al estimated the incidence of pulmonary involvement in spondylitis to be 28 out of 2080 patients, representing $3.1 \%$, corresponding in most cases to apical fibrosis [6].

It was only in 1997, with the use of computed tomography (CT) scans that Casserly and al [7] described the other pulmonary diseases of spondyloarthritis, they demonstrated that most of the abnormalities are not visible on standard radiography. In fact, 4 out of 26 patients had radiological abnormalities while CT scan revealed abnormalities in 19 patients.

Since then, many studies using thoracic CT in the detection of pleuropulmonary lesions in spondylarthritis have been carried out. Overall, the abnormalities encountered were bronchiectasis, emphysema, micronodules and apical fibrosis.

In addition to these disorders, non-specific but frequent lesions can be found in the course of PsA and skin psoriasis. Indeed, available data suggest that about $70 \%$ of psoriasis patients have some degree of comorbidity [8], including COPD and sarcoidosis.

Some studies report an association between psoriasis and COPD. Chiang and al. found that patients with psoriasis had a 2.35 times greater risk of developing COPD than the control group [9]. Further work [10-11] does not confirm these results. There does not appear to be a causal relationship between psoriasis and COPD, since smoking is a documented risk factor for both diseases.

Sarcoidosis is an inflammatory disease involving the formation of granulomas throughout the body, usually in the lungs and lymph glands. The cause of sarcoidosis is still unknown, but researchers have hypothesized that sarcoidosis and psoriasis may share common disease pathways because the two diseases can coexist in patients 
[12,13]. In addition, psoriasiform lesions have been reported in cases of sarcoidosis [95].In our series, we diagnosed 6 cases of COPD and 1 case of sarcoidosis in patients with psoriatic arthritis having cutaneous psoriasis.

In their study published in 1997, about mortality during psoriatic arthritis, Wong and al reported among the causes of death: respiratory diseases $(21 \%)$, pneumonia $(15 \%)$ or chronic obstructive pulmonary disease $(6 \%)$. The risk of death from lung disease was significantly higher than in the general population [14]. It should be noted that this series is the only one to report this over-mortality during psoriatic arthritis compared to the general population.

On the other hand, although the pathophysiological mechanisms are not fully understood, a growing number of publications demonstrate the high frequency of lung damage during chronic inflammatory bowel disease (IBD) $[15,16,17]$ Similarly, it has been found that patients with chronic lung disease have an increased risk of developing gastrointestinal inflammatory disease $[18,19]$. There are several hypotheses about connections within the "lungintestinal axis". The lungs and intestines are derived from the same embryonic cell line [20]. They share a common epithelium, and so they can develop similar inflammatory reactions because of these common anatomical features.

Another possibility explaining this link is the shared antigen theory. The intestinal and pulmonary epithelium are exposed to the same antigens. Thus, this shared exposure can induce similar inflammation in both systems [21]

As lung disease may follow a course independent of intestinal inflammation, symptoms may be overt or subclinical [22]. Manifestations of pulmonary airway involvement range from bronchitis to bronchiolitis, bronchiectasis, tracheal stenosis and asthma. Lung parenchyma includes interstitial lung diseases such as mononuclear bronchiolitis with granulomatous lesions, organized pneumonia, cellular interstitial pneumonia with scattered granulomas and acute bronchiolitis with areas resembling bronchopneumonia and abscess formation [23]. Necrotic pulmonary nodules are rare in Crohn's disease, but have been described in pulmonary diseases related to ulcerative colitis.

In our series, 11 patients out of 22 IBD cases developed lung involvement; dominated by interstitial syndrome in $54.5 \%$ of cases. The other lesions were bronchiectasis in 2 cases, 1 case of emphysema, 1 case of adenopathy and 1 case of pulmonary micronodule.

In addition, lung lesions were observed to be more frequent in older patients. The mean age in patients with CT lung damage was $52.43+/$ - 11.75 compared to $42.98+/$ - 11.54 in patients without CT lung damage. This is statistically significant $(\mathrm{p}=0.049)$.

In the literature, the frequency of CT lung involvement is rather correlated with the age of the AS. Senocak et al [24] also found this correlation between chest $\mathrm{CT}$ results and the duration of disease progression. They found that these lesions were more characteristic of long-standing AS. In our study, the mean duration of progression of AS in the group with CT abnormalities was $9.84( \pm 7.92)$, which was greater than in the group without CT abnormalities (7.89 $\pm 7.15)$, but the correlation with the presence of pulmonary densitometric abnormalities was not statistically significant $(\mathrm{p}=0.201)$.

In this study, no statistically significant difference was observed in the frequency of CT lesions between smokers and non-smokers $(\mathrm{p}=0.105)$. Most studies $[25,26,27]$ that included patients who smoked did not also find a difference between smokers and non-smokers. In the study by Baser et al [28], 82 patients were initially evaluated; fifty-six patients were excluded from the study due to a history of tuberculosis, previous pneumonia, exposure to inhaled dust or gas, smokers or patients using a drug that could affect pulmonary parenchyma; the remaining 26 patients were included in the study. They detected CT scan abnormalities in 13 of the 26 patients. These results confirm that pulmonary abnormalities in AS cannot be attributed to smoking. Similarly for psoriatic arthritis and inflammatory bowel disease, there is no evidence incriminating the role of smoking in the development of specific lung abnormalities.

Most studies have found no relationship between respiratory function tests and parenchymal damage seen on CT scans $[28,26,29,30]$. Baser et al assessed respiratory function in 26 patients with AS .8 had a restrictive syndrome regardless of the CT abnormalities found.

These results are not consistent with our findings. In our study, the restrictive syndrome was found in 49 patients, 39 of whom had CT lesions. This difference was statistically significant, which may be explained by the fact that most 
patients with chest CT abnormalities had long-standing AS at the stage of ankylosis, which may be the cause of the restrictive syndrome.

On the other hand, our study demonstrated a clear relationship between reduced spinal mobility, especially dorsal mobility, and the restrictive syndrome in our patients $(\mathrm{p}=0.002)$ (Table 3$)$. These results confirm the hypothesis of an association between musculoskeletal limitations and restrictive respiratory disorder in AS, as has been shown in numerous previous studies [31]. Indeed, spondylitis causes ankylosis of the thoracic vertebrae and the costovertebral, costo-transverse, sterno-clavicular and manubrio-sternal joints, producing a stiffening of the thorax responsible for restrictive abnormalities, which are frequently associated with a limitation of thoracic amplification. This underlines the major interest of including early respiratory physiotherapy in the rehabilitation programme for spondylarthritis patients $[32,33]$. Home exercises, especially self-programs, are effective, but physical treatment with supervised exercises is preferable.

\begin{tabular}{|l|l|l|l|l|}
\hline & & SpA with ventilatory anomaly & SpA without ventilatory anomalies & P \\
\hline & & $(\mathbf{n = 4 9 )}$ & $(\mathbf{n = ~ 8 1 )}$ & \\
\hline \multirow{3}{*}{ Axial damage (\%) } & Lombalgie & $35(71,4 \%)$ & $33(39,2 \%)$ & 0,01 \\
\cline { 2 - 5 } & dorsalgie & $30(61,2 \%)$ & $23(27,4 \%)$ & 0,000 \\
\cline { 2 - 5 } & Cervicalgie & $15(30,6 \%)$ & $11(13 \%)$ & 0,014 \\
\hline \multirow{2}{*}{$\begin{array}{l}\text { Peripheral damage } \\
(\%)\end{array}$} & Arthralgies & $41(83 \%)$ & $78(92,8 \%)$ & 0,096 \\
\cline { 2 - 4 } & Arthrites & $27(55,1 \%)$ & $52(62 \%)$ & 0,441 \\
\hline \multicolumn{2}{|l|}{ enthesical damage, $\mathbf{n}(\mathbf{\%})$} & $16(72,4 \%)$ & $58(71,6 \%)$ & 0,81 \\
\hline
\end{tabular}

Table 3:- Comparison between patients with and without a ventilatory disorder according to the distribution of rheumatic involvement (axial, peripheral and enthesic).

Recent recommendations in the field state that non-drug treatment of spondyloarthritis should routinely include physiotherapy exercises including stretching, muscle strengthening and breathing work. These exercises should be started as early as possible in the history of the disease, and regular exercise over the long term is particularly important [34].

Concerning medical treatment, lung damage during the course of spondyloarthritis does not change the therapeutic protocol of the disease.

Conventional treatments (so-called "conventional" DMARDs) have no indication for isolated axial or enthesic manifestations. However, they can be considered in the case of peripheral involvement and may also be effective for extra-articular manifestations, including pulmonary involvement [32]. Monitoring and dose adjustment of some treatments such as methotrexate require the assistance of a pneumologist to optimize control and long-term prognosis.

Biologic treatments, particularly anti-TNF alpha antibodies, have been shown to be effective in various forms of the disease. Its effect on the parenchymal lung disease of spondyloarthritis is not yet known. Restrictive syndrome is the only pulmonary abnormality that has been shown to improve with anti-TNF therapy [35].

In patients with psoriatic arthritis whose clinical presentation mimics rheumatoid arthritis (RA), it is interesting to note that there is no evidence of increased lung involvement. However, patients with psoriatic arthritis still have a susceptibility to develop drug-related lung disease when exposed to agents such as MTX or anti-TNF, although this may be to a lesser degree than that seen in rheumatoid arthritis [36].

\section{Conclusion:-}

Our study confirmed the superiority of thoracic CT over standard radiography in the detection of pulmonary lesions during Spondylarthritis (SpA), as already proven in SA, as these lesions are often asymptomatic and not detected by standard radiography.

With the advent of chest CT, a wide variety of lung lesions have been objectified in up to $80 \%$ of Spondyloarthritic patients. 
The most common lesions are apical fibrosis, emphysema, bronchiectasis, frosted glass images, micronodules, pleural thickening and thickening of the bronchial wall. These lesions are common in late and severe AS. Smoking alone cannot explain the appearance of these CT lung lesions, since these abnormalities were found in both smokers and non-smokers among our patients.

The presence of these abnormalities does not currently modify the management, subject to rigorous monitoring, particularly when using conventional background treatment such as methotrexate or biotherapies.

\section{Conflict of interest :}

The authors declare that they have no conflict of interest.

\section{Reference:-}

1. El Maghraoui A. Pleuropulmonary involvement in ankylosing spondylitis. Joint Bone Spine 2005;72:496-502.

2. Ozlem Senocak, Metin Manisalı, Dinc Ozaksoy, Can Sevinc, Elif Akalın. Lung parenchyma changes in ankylosing spondylitis: demonstration with high resolution CT and correlation with disease duration.

3. Kiris A, Ozgocmen S, Kocakoc E, Ardicoglu O. Lung findings on high resolution CT in early ankylosing spondylitis. Eur J Radiol. 2003 Jul ;47(1):716.

4. H. M. Fenlon, I. Casserly, S. M. Sant, and E. Breatnach, "Plain radiographs and thoracic high-resolution CT in patients with ankylosing spondylitis," American Journal of Roentgenology, vol. 168, no. 4, pp. 1067-1072, 1997.

5. El Ghoul, N. Rouetbi, S. Joobeur, N. Skhiri, S. Cheikh Mhamed, A. El Kamel. Spontaneous pneumothorax associated with ankylosing spondylitis. Revue de pneumologie clinique (2012) 68, 266-268.

6. Rosenow E, Strimlan CV, Muhm JR, Ferguson RH. Pleuropulmonary manifestations of ankylosing spondylitis. Mayo Clin Proc. 1977 Oct ;52(10) :641-9.

7. Casserly IP, Fenlon HM, Breatnach E, Sant SM. Lung findings on high-resolution computed tomography in idiopathic ankylosing spondylitis--correlation with clinical findings, pulmonary function testing and plain radiography. Br J Rheumatol. 1997 Jun;36(6):677-682.

8. Machado-Pinto J, dos Santos M, Bavoso D. Psoriasis: new comorbidities. An Bras Dermatol 2016 JanFeb;91(1):8e14

9. Chiang YY, Lin HW. Association between psoriasis and chronic obstructive pulmonary disease: a populationbased study in Taiwan. J Eur Acad Dermatol Venereol 2012 Jan;26(1):59e65.

10. Yeung H, Takeshita J, Mehta NN, et al. Psoriasis severity and the prevalence of major medical comorbidity: a population-based study. JAMA Dermatol 2013 Oct;149(10):1173e9.

11. Li X, Kong L, Li F, et al. Association between psoriasis and chronic obstructive pulmonary disease: asystematic review and meta-analysis. PLoS One 2015 Dec 23;10(12):e0145221.

12. Wanat KA, Schaffer A, Richardson V ,et al. Sarcoidosis and psoriasis: a case series and review of the literature exploring co-incidence vs coincidence. JAMA Dermatol 2013 Jul;149(7):848-52.

13. Nikolopoulou M, Katsenos S, et al. Pulmonary sarcoidosis associated with psoriasis vulgaris: coincidental occurrence or causal association? Case report. BMC Pulm Med 2006;6:26-7.

14. WONG K, GLADMAN DD, HUSTED J, LONG J, FAREWELL VT: Mortality studies in psoriatic arthritis. Results from a single centre. I. Risk and causes of death. Arthritis Rheum 1997; 40: 1868-72.

15. Zhao Y, Wang J, Liu Z, Lin H, Shi Y, Sun X. Pulmonary dysfunction in 114 patients with inflammatory bowel disease. Medicine (Baltimore). 2017;96(18), e6808

16. Camus P, Piard F, Ashcroft T, Gal AA, Colby TV. The lung in inflammatory bowel disease. Medicine (Baltimore). 1993;72(3):151-83.

17. MahadevaR,WalshG,FlowerCD,ShneersonJM.Clinicaland radiological characteristics of lung disease in inflammatory bowel disease. Eur Respir J. 2000;15:41-8.

18. Raj AA, Birring SS, Green R, Grant A, de Caestecker J, Pavord ID. Prevalence of inflammatory bowel disease in patients with airways disease. Respir Med. 2008;102(5):780-5.

19. Brassard P, Vutcovici M, Ernst P, et al. Increased incidence of inflammatory bowel disease in Québec residents with airway diseases. Eur Respir J. 2015;45(4):962-8.

20. Vutcovici M, Brassard P, Bitton A. Inflammatory bowel disease and air- way diseases. World J Gastroenterol. 2016;22(34):7735-41.

21. Tulic M, Piche T, Verhasselt V. Lung-gut cross-talk: evidence, mechanisms and implications for the mucosal inflammatory diseases. Clin Exp Allergy. 2016;46(4):519-28. 
22. Ji X-Q, Wang L-X, Lu D-G. Pulmonary manifestations of inflammatory bowel disease. World J Gastroenterol WJG. 2014;20:13501-13511.

23. Casey MB, et al. Noninfectious lung pathology in patients with Crohn's disease. Am J Surg Pathol. 2003;27:213-219.

24. Ozlem Senocak, Metin Manisalı, Dinc Ozaksoy, Can Sevinc, Elif Akalın. Lung parenchyma changes in ankylosing spondylitis: demonstration with high resolution CT and correlation with disease duration.

25. Abdellah El Maghraoui. Pleuropulmonary involvement in ankylosing spondylitis. Revue du rhumatisme 72 (2005) 1263-126.

26. Remzi A, Senay O, Ahmet S, Selda S, Meltem T, Levent K, Huseyin O. Comparison of early and late pleuropulmonary findings of ankylosing spondylitis by high-resolution computed tomography and effects on patients' daily life. Clin Rheumatol (2005) 24 : 22-28.

27. Kiris A, Ozgocmen S, Kocakoc E, Ardicoglu O. Lung findings on high resolution CT in early ankylosing spondylitis. Eur J Radiol. 2003 Jul ;47(1) :716.

28. Baser S, Cubukcu S, Ozkurt S, et al. Pulmonary involvement starts in early stage ankylosing spondylitis. Scand J Rheumatol $2006 ; 35: 325-327$.

29. Turetschek K. Ebner W. Fleischmann D. Wunderbaldinger P. Erlacher L. end al. Early pulmonary involvement in ankylosing spondylitis: assessment with thin-section clinical radiology. 2000 Aug;55(8):632-6.

30. Casserly IP, Fenlon HM, Breatnach E, Sant SM. Lung findings on high-resolution computed tomography in idiopathic ankylosing spondylitis--correlation with clinical findings, pulmonary function testing and plain radiography. Br J Rheumatol. 1997 Jun;36(6):677-682.

31. Berdal G, Halvorsen S, Van Der Heijde D, et al. Restrictive pulmonary function is more prevalent in patients with ankylosing spondylitis than in Matched population controls and is associated with impaired spinal mobility: a comparative study. Arthritis Res Ther 2012 ;14 : R19.

32. Daniel Wendling, Cédric Lukas, Julien Paccou, Pascal Claudepierre, Laurence Carton, Bernard Combe, Philippe Goupille, Francis Guillemin, Christophe Hudry, Corinne Miceli-Richard, Maxime Dougados. Recommandations de la société française de rhumatologie (SFR) pour la prise en charge en pratique courante des malades atteints de spondyloarthrite. Revue du rhumatisme 81 (2014 )6-15.

33. Zochling J, van der Heijde D, Burgos-Vargas R, et al. ASAS/EULAR recommendations for the management of ankylosing spondylitis. Ann Rheum Dis2006; 65:442-52.

34. Ozgocmen S, Akgul O, Altay Z, et al. Expert opinion and key recommendations for the physical therapy and rehabilitation of patients with ankylosingspondylitis. Int J Rheum Dis 2012; 15:229-38.

35. Dougados M, Braun J, Szanto S, et al. Efficacy of etanercept on rheumatic signsand pulmonary function tests in advanced ankylosing spondylitis: results ofa randomised double-blind placebo-controlled study (SPINE). Ann Rheum Dis2011;70:799-804.

36. Conway R, Low C, Coughlan R, et al. Methotrexate use and risk of lung disease in psoriasis, psoriatic arthritis, and inflammatory bowel disease: systematic literature review and meta-analysis of randomised controlled trials. BMJ Br Med J March 2015;350:h1269. 